Article

\title{
Resilience for Whom? A Case Study of Taiwan Indigenous People's Struggle in the Pursuit of Social-Ecological Resilience
}

\author{
Hsing-Sheng Tai ${ }^{1,2}$ \\ 1 Department of Natural Resources and Environmental Studies, National Dong Hwa University, Shoufeng, \\ Hualien 97401, Taiwan; hstai@gms.ndhu.edu.tw; Tel.: +886-3-890-3342 \\ 2 Center for Interdisciplinary Research on Ecology and Sustainability, College of Environmental Studies, \\ National Dong Hwa University, Shoufeng, Hualien 97401, Taiwan
}

Received: 28 July 2020; Accepted: 8 September 2020; Published: 10 September 2020

\begin{abstract}
While the notion of social-ecological system resilience is widely accepted and applied, the issue of "resilience for whom" is clearly ignored. This phenomenon has also occurred in Taiwan. This article explores the roots of, and a possible solution to, this issue through a case study in the context of Taiwan's indigenous peoples. The Danungdafu area, the focal social-ecological system, was studied. Qualitative research methods and an action-oriented research approach were employed. For a long period, the central government shaped the political, economic, social, institutional, and ecological contexts; dominated resilience discourses and determined the problem-framing and problem-solving agenda; defined the scale and levels at which social-ecological system governance issues were addressed; and determined the knowledge system used to define and solve problems. After 2011, a new participatory governance regime emerged. Multiple stakeholders, including indigenous communities, began to contribute to resilience discourses and influenced governance and trade-offs among differing governance goals. However, under the established structures dominated by Han people, indigenous views, rights, and well-being continue to be ignored. Affirmative action is required to recognize and safeguard indigenous rights. A practical institutional pathway is available to facilitate the transformation from "resilience for mainstream society" to "resilience for indigenous people" in indigenous territories.
\end{abstract}

Keywords: indigenous people; resilience; social-ecological system; Taiwan

\section{Introduction}

In the context of global changes, the influence of resilience thinking has expanded rapidly over the past two decades. Academia, governments, civil society, and even the private sector have embraced the notion of social-ecological system resilience and have applied it to a wide range of sustainability issues [1]. Resilience here is defined as "the capacity of a social-ecological system to absorb a spectrum of shocks or perturbations and to sustain and develop its fundamental function, structure, identity, and feedbacks through either recovery or reorganization in a new context" [2]. As this definition demonstrates, from the origin of the concept, social systems and ecosystems have been regarded as an inseparable and closely interacting system [1,3]. Because of the nature of the social system and the need to distinguish which system states are desirable or undesirable when undergoing adaptation and transformation, resilience is an inherently value-laden concept [1,4]. Similar to the concept of sustainability, resilience concerns the well-being of human society at different levels $[5,6]$. It must therefore address related social issues, including value judgments, power, political and social processes, distribution, inequality, collective action, and human agency. Thus, resilience should address the following core questions: resilience of what to what? and resilience for whom? $[1,7,8]$. 
As a core issue of resilience, the issue of "resilience for whom" should be addressed explicitly, especially in relation to disadvantaged and marginalized groups in the social system (see, for example, [9]). Numerous scholars, however, have stated that the extent to which this issue has been addressed in resilience research remains far from adequate [10-14]. More precisely, deficiencies are reflected in several interrelated subtopics.

Power is a key issue in the resilience and governance of social-ecological systems. Unequal power relations between different social groups are often the root cause of environmental and resilience problems, and the deterioration of the environment and resilience often worsens inequalities in distributions of power [10]. Power directly involves politics. Power inequality not only involves contemporary political and social processes but can often be traced back to the colonial period and the period of state-building [11]. Power and politics shape politically advantaged and disadvantaged groups and ethnic, class, economic, cultural, and gender boundaries and affect the capacity of groups to respond to disturbances. Generally, the groups most vulnerable to disturbances are also the most politically powerless [11]. Not only does inequality cause low resilience in certain groups, it also reduces the possibility of rebuilding resilience [13]. This means that power, politics, and ethical considerations are, among others, the main driving factors affecting the resilience of social-ecological systems. They should be deliberately included in any analysis rather than be intentionally or unintentionally ignored [8].

Considering power, politics, value judgments, and ethical aspects, a number of major issues emerge when people attempt to address the question "resilience for whom" in a specific case: (1) Who and what drivers shape unequal political, economic, social, institutional, and ecological contexts $[15,16]$; (2) Who dominates resilience discourses and determines problem-framing and problem-solving agendas [10,17]; (3) Who defines the scale and levels at which social-ecological system governance issues are addressed [10]; (4) Who determines the knowledge system used to define and solve problems [10]; (5) Who are the major agents of the governance process, who exerts influences on governance and why $[18,19]$; (6) Who decides trade-offs among conflicting resilience governance goals [10]; and (7) Whose rights should be actively recognized and safeguarded, and what measures can people take to improve this process of recognizing and protecting rights [13,20-22].

Compared with international trends, Taiwan has recognized and applied the concept of social-ecological system resilience relatively late. Only about 10 years have passed since it became popular. Even so, the concept of resilience has already been used in numerous fields. Taking Taiwan's central governmental sectors as an example, the Ministry of Science and Technology recently completed a disaster prevention policy proposal titled "Resilient Cities under Extreme Disasters" [23]. The Council of Agriculture has moved toward resilient agriculture [24], and the Taiwan Forestry Research Institute of the Council of Agriculture has called for pursuing resilient urban forests [25]. The Ministry of the Interior has promoted the concept of resilient communities [26]-. Also, the Ministry of Economic Affairs made "Resilient Water Resources Management" one of its major policies [27]. These examples suggest that the concept of resilience has penetrated main public policy fields and exerted a significant influence on policy discourses. However, although nearly all sectors of Taiwanese society have quickly embraced resilience notions, many profound theoretical and practical issues have emerged. As the review in the previous paragraphs argues, the "resilience for whom" issue is a critical topic that is rarely addressed. Similar phenomena can be seen in Taiwan, and a greater degree of attention is urgently needed to correct deficiencies that may have occurred at the level of theoretical understanding as well as policy discourse and implementation.

This article aims, through a case study in the context of Taiwan indigenous peoples, to explore the "resilience for whom" issue. It argues that so far, discourses and practices related to resilience in real cases in Taiwan have mainly focused on ecological resilience and the well-being of mainstream society, whereas the views, rights, and well-being of indigenous peoples are largely ignored or at least underestimated. These phenomena are deeply rooted in the political, economic, institutional, social, and cultural structures dominated by the mainstream Han society. I argue that, in Taiwan's pursuit of social-ecological resilience, this is a major deficiency that cannot be ignored. Proactive measures are 
required to correct this unacceptable injustice. Despite seemingly insurmountable obstacles, this article also suggests possible institutional pathways that could help solve the problem of resilience for whom in the context of Taiwan.

The article is organized as follows. After explaining the significance of the research background, research questions, and purpose of the work in the first section, the article briefly introduces the background of the studied case in the second section. Section 3 describes the research methodology used. In Section 4, various subtopics in the issue of resilience for whom are analyzed according to the sequence of the case's evolution. The major findings of the case study are discussed in Section 5 . The final section summarizes the conclusions. Based on the real circumstances of Taiwan presented in this case, this article also proposes possible institutional approaches to improve the problem-solving process.

\section{Case Background}

The focal social-ecological system studied in this paper is the Danungdafu Area (hereinafter referred to as DFA), Hualien County, Taiwan. The ecosystem included in the focal system is the Danungdafu plain forests, located in the middle of the East Rift Valley $\left(23^{\circ} 36^{\prime} \mathrm{N}, 121^{\circ} 24^{\prime} \mathrm{E}\right)$, with the East Coastal Mountain Range in the east and the Central Mountain Range in the west, and with a total area of 1250 hectares. The social system encompasses the villages that are adjacent to, and have a close relationship with, the plain forests area, including indigenous communities (Tafalong, Fata'an, Fahol, Okakay, Sado) and communities where Han people, making up the majority of the population, and indigenous people live together (Daho, Fuhsing, Fuyuan, Galiwan; see Figure 1).

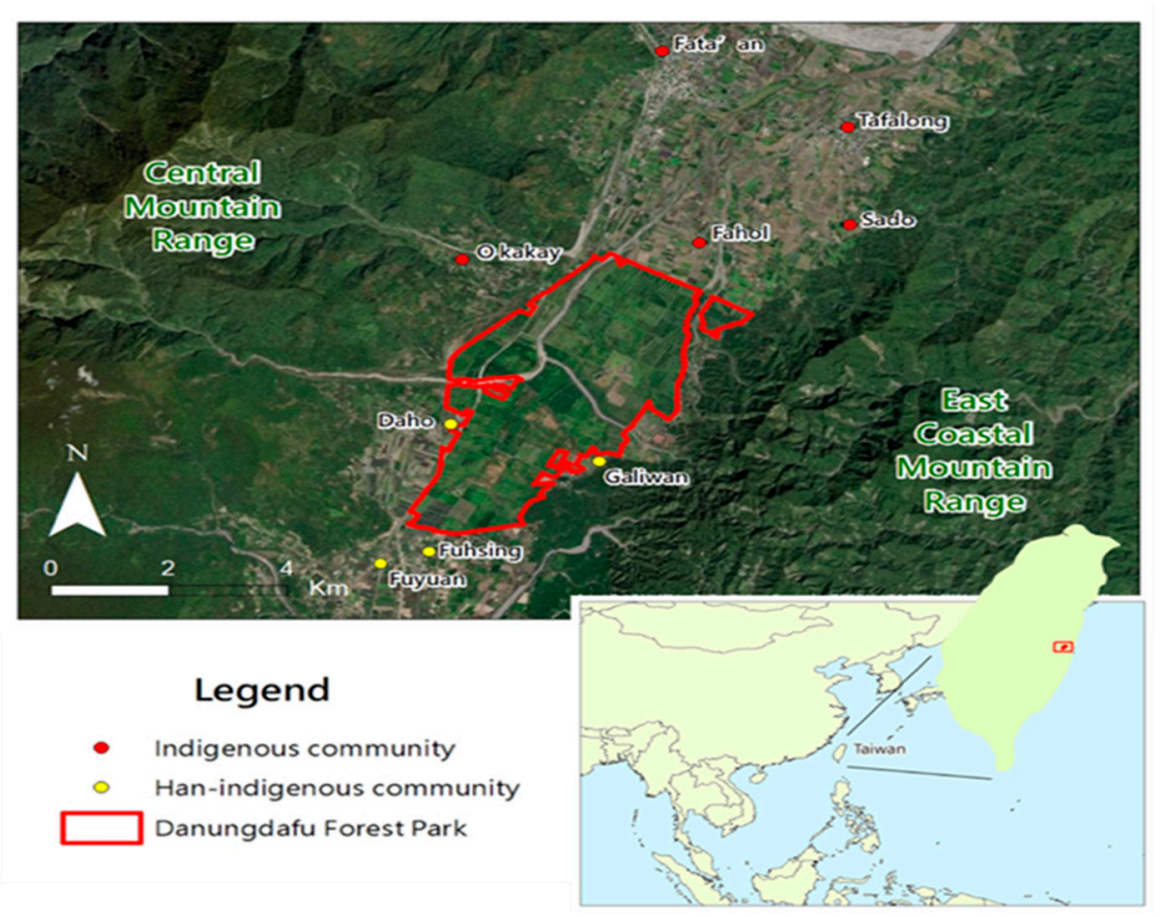

Figure 1. Danungdafu Area (DFA). The area enclosed by the red border is Danungdafu Forest Park. Red dots represent indigenous communities (Tafalong, Fata'an, Fahol, Okakay, Sado), and yellow dots represent Han-indigenous communities (Daho, Fuhsing, Fuyuan, Galiwan), where Han people comprise the majority of the population.

The DFA case is a particularly complex but representative case for the issue of the land and natural resource rights of indigenous peoples in Taiwan. Considering indigenous land and natural resource rights, the Western plains of Taiwan are currently mainly used by Han people with private land rights. Therefore, in terms of political reality, making these plains the main target of indigenous peoples' land movement is difficult. The central mountainous region, where mainly indigenous settlements 
are located and most lands are designated as protected areas or state-owned forests, is generally considered to be, with less controversy, traditional territories of indigenous peoples. Issues in the Eastern plain region, especially the Eastern Rift Valley region, pose the greatest challenge. This was the final area taken by Han settlers and the modern state regime; many Han people moved to this area only at the end of the nineteenth century [28]. Today, eastern Taiwan remains the region with the highest proportion of indigenous people. In the Eastern Rift Valley area, numerous indigenous villages and Han-dominated communities are present. Over the past 100 years, the state nationalized a large proportion of lands in the area, lands which were once the traditional territories of indigenous peoples, and a considerable portion of the lands became private property in the process of privatization. These realities pose major challenges to the political claims of the indigenous "Return Our Land" movement and to the implementation of the Indigenous Historical Justice and Transitional Justice Policy that started in the first term of the current president, Tsai Ing-Wen, in 2016 [29].

\section{Methodology}

This study is part of an integrated research project titled "Social-Ecological System Resilience in Central Eastern Rift Valley: The Role of Danungdafu Forestation Area." It is based mainly on the research work of the governance subproject; the project as a whole covers numerous aspects of natural and social sciences. The goals of the integrated project are to study the resilience dynamics of a specific social-ecological system and to promote resilience-oriented governance based on the research findings. More specifically, the research team (hereafter referred to as the NDHU Team) followed the Resilience Assessment Framework suggested by the Resilience Alliance. It includes five main iterative and reflexive stages [30], as follows:

- Describing the system

- Understanding system dynamics

- Probing system interactions

- Evaluating system governance

- Acting on the assessment

The Resilience Assessment Framework is applied to the DFA case; this research integrates iterative feedback processes, from building a knowledge base to taking appropriate actions, and is therefore a form of action-oriented research. Governance issues should also be studied, including formal institutions and informal norms, multiple interests and value judgments, human organizations, social networks and interpersonal interactions, collective actions, and social movements. All these issues have social, economic, political, and ecological contexts. To study the complex interaction of the various contexts and factors mentioned, qualitative research methods including in-depth interviewing, participatory observation, and focus group meetings were employed. The research was conducted from August 2013 to April 2020.

\section{The Case Study}

\subsection{Political, Social, Economic, Institutional, and Ecological Contexts}

Before the end of the nineteenth century, the DFA was the traditional territory of Amis people [31,32]. Amis people engaged in slash-and-burn farming and hunting to maintain their livelihoods. After 1895, the Japanese government's policy of nationalizing all "ownerless" land completely changed the fate of Taiwan's indigenous peoples [33]. In the 1910s, the Japanese state entered and ruled the DFA. The state nationalized indigenous peoples' land and used it for commercial sugar cane plantations at the expense of indigenous people. Amis people who lived there were expelled, causing them to be displaced to marginal areas of the East Coastal Mountain Range and the Central Mountain Range. The evictions led to the disintegration of indigenous communities. Furthermore, these marginal lands are generally 
vulnerable to natural disasters and have low land productivity, leading to the prevailing economic and social predicament of indigenous people that continues today $[32,34]$.

After the 1910s, DFA land and surrounding communities were transformed from a social-ecological system with high biological and livelihood diversity to farmland growing a single commercial crop that largely depended on the international trade-oriented sugar economy. Because sugar production required intensive manpower, Han people began to settle in the area in large numbers, forming mixed settlements of Han-indigenous communities, which greatly changed the population composition of the area. Changes in the population composition also profoundly affected the attributes of the social system, including today's actors and collective actions related to governance.

After the Second World War, the Taiwanese government took full control of Japanese land and industrial assets in Taiwan and followed the same policy of state ownership of land. The de jure public land in the DFA was received by the state-owned Taiwan Sugar Company (hereafter referred to as TSC) established in 1946 [35]. Therefore, the DFA maintained the sugar-based social and economic structure that originated during Japanese rule, with a similar central government-led governance system. In the 1980s, the international price of sugar dropped significantlyand domestic production costs rose sharply, and the industry began to shrink. In 1995, Taiwan applied to join the World Trade Organization, and for this reason it removed some protection measures for the sugar industry. Sugar production finally ceased in 2002 [35], and DFA land was temporarily idle.

DFA land soon faced changes from the implementation of government policies. To cope with the impact of Taiwan's World Trade Organization membership on domestic agriculture, the Council of Agriculture has promoted the "Plain Land Afforestation Project" since 2002 to subsidize the afforestation of agricultural land. Other arguments promoting plain land afforestation include increasing the forest coverage of the plains, enhancing carbon sequestration, improving environmental quality and aesthetics, conserving biodiversity, and enhancing the potential for timber self-sufficiency [36]. DFA land thus rapidly changed from idle farmland to an afforestation area. In 2011, under the guidance of government policies, the DFA afforestation area was designated the "DFA Forest Park," one of the three largest plain forest parks in Taiwan. The main policy objectives were to provide ecosystem services and promote tourism. The Forestry Bureau of the central government is responsible for the management of the forest park, although the public enterprise TSC continues to own the land and forest property rights. Thus, central government policy over the past 100 years has determined the current characteristics of the DFA social-ecological system and the fundamental structure of its governance.

\subsection{Problem Framing, Discourses, and Scale Issues}

From the early 2000s to the early 2010s, with the growth of the forest and the opening and operation of the forest park, stakeholders with different positions developed conflicting views on the park. As the official managing authority of the park, the Forest Bureau has always looked at management issues from a national perspective. In the management plan of the DFA forest park, the Hualien Branch of the bureau clearly stated the following objectives: enhancing carbon sequestration, improving environmental quality and aesthetics, conserving biodiversity, promoting ecotourism, environmental education, and local development, and conserving Amis culture [37]. These goals relate mainly to the provision of national-level public goods and regional common-pool resources. The main target beneficiaries of these ecosystem services are the general public of the country. Local residents may also benefit from these services, and local development is indeed listed as a major goal, but, in fact, this is at most only a side effect of the real motivation for designating a forest park, namely environmental conservation. Notably, in the problem framing and policy discourse of the management plan, no particular consideration was given to the historical context of the land grab and the costs that local residents had to bear, especially in terms of indigenous rights.

As one of few large forests in otherwise over-developed plain areas, the DFA park's potential role in biodiversity conservation also attracted the attention of academics and environmental nongovernmental organizations (NGOs). In addition to helping to conserve rare species in the plains, the main focus 
of discussion is whether the DFA is a potential ecological corridor between the protected national forests of the Central and the East Coastal mountain ranges. Some researchers have studied the topic. Individual academics and NGOs have also presented proposals for an ecological corridor; they have advocated enhancing the protection of DFA forests and minimizing human use. As the major government authority in charge of nature conservation, the Forestry Bureau has expressed a high level of interest in the idea of an ecological corridor. Researchers have since determined that the DFA has indeed begun to function as an ecological corridor [38,39]. The Forestry Bureau launched a national ecological network plan in 2018 that treated the DFA forest as a critical corridor in eastern Taiwan.

The Forestry Bureau, some scholars, and environmental NGOs consider DFA governance issues mainly from environmental perspectives; by contrast, the TSC and local communities are primarily concerned about economic utilization and local livelihoods. TSC is a government-owned enterprise that legally owns the land and forests of the DFA forest park. It essentially expects and strives to reap economic benefits through a more intensive use of land and forest resources. However, it must also follow the government's current conservation-oriented policy.

Indigenous communities are primarily concerned with the ownership of land and natural resources rights. Their main political appeal to the state regarding DFA land is that the state should return the land to them and let them decide autonomously how to use the land. Most indigenous residents advocate agricultural use, tourism development, and land use types based on indigenous culture, like ethnic botanical gardens that can provide opportunities for daily edible plant collection and possible tourism sightseeing spots [40]. According to the land ethics of the indigenous people, they have generally agreed that land use should take environmental perspectives into consideration. The point, however, is that local indigenous communities should have autonomy in deciding how to balance livelihoods, cultural revitalization, and conservation perspectives.

In addition to villages whose populations are mainly indigenous, multiple communities near the DFA mostly comprise Han people, including descendants of past sugar industry workers and a small number of new residents who moved here from urban West Taiwan. These Han-dominant communities have no special claim on land rights issues, and they also respect the status quo of national land ownership and forest park policy. Their main expectation is that given the economic and social issues prevailing in rural areas, the forest park may bring more economic and employment opportunities to local communities through deliberate planning and improved management. Most local Han people have consciously avoided talking about indigenous peoples' land rights. They are, in private, generally not sympathetic to indigenous claims, but they are reluctant to publicly express their true thoughts for political reasons. Some people in these communities, especially new residents -who pursued a better natural environment and the younger generation of residents with urban work experience, express strong environment-friendly values. This group of people therefore emphasizes the ecological conservation function of the forest park and is happy to see the park play a larger role in conservation. They also generally look forward to the development of conservation-based economic activities such as ecotourism.

\subsection{Development of Governance Network after 2011}

On May 21, 2011, the forest park officially opened. Then-President Ma Ying-Jeou presided over the opening ceremony. A number of indigenous people protested fiercely during the ceremony and made the political claim "Return Our Land." This was the first time that the DFA case had attracted national attention. This protest, as well as the political and social changes in Taiwan behind the incident, including the indigenous movement, had a profound impact on the governance of the DFA. Many indigenous people began to challenge the existing land tenure arrangement and governance regime. However, the reality is that with these seemingly insurmountable structural barriers, real progress after the protest was sluggish. The Forestry Bureau did attempt to start a dialogue with indigenous communities after the protest, with the motivation of reducing tension. 
However, due to their enormous differences in views and because of long-accumulated conflicts and mistrust, the dialogue between the two parties ended again in conflict.

Research by the NDHU Team highlighted the characteristics of the governance regime of the DFA in the early 2010s. Overall, governance of the DFA was characterized as (1) nonparticipatory and nondeliberative; (2) monocentric, with a two-tier structure of dominant state and weak communities; (3) unjust, with upward accountability; and (4) loose governance networks [41]. The issue of injustice affects all local communities, but, undoubtedly, the most affected are indigenous communities. These characteristics can explain the serious defects of the governance regime at the time, including indigenous and local knowledge not being included in the governance process and a lack of consideration of social and cultural diversity. Another serious problem involves scale mismatch: the state-dominated governance regime views issues from a national perspective, whereas local communities view issues from their own perspective; DFA governance issues cannot be addressed at adequate governance levels based on the nature of the issues [41].

Even if the existing governance regime is far from ideal, the uninterrupted indigenous movement and changes in the Forestry Bureau have led to the possibility of gradual change. The indigenous movement has forced the Forestry Bureau to start considering indigenous people's views, at least in specific cases such as the DFA. Furthermore, influenced by international trends in conservation, the Forestry Bureau has begun to adopt measures that include more local views and encourage local involvement. For example, community forestry policy is a typical approach that has been widely applied since 2002 [42]. The same situation applied to the DFA after 2011. Specifically, with the DFA, changes were also prompted by action-oriented academic research initiatives. As described in the previous paragraph, the researchers identified flaws in the existing governance regime. The NDHU Team accordingly launched a series of action-oriented initiatives. The basic goal was to collaborate with all types of stakeholders and proactively pursue a better governance mode. This new mode should be superior to the previous governance regime for the following governance attributes: participation, deliberation, justice, accountability, diverse knowledge base, and scale match.

Throughout the 2010s, under the influence of various factors mentioned in the previous paragraph and with the involvement of diverse actors, DFA's governance network structure underwent significant changes. In this section, the interaction of actors and the subsequent development of the governance network are analyzed. Four stages of network development emerged.

\subsubsection{Governance Network in 2011}

In 2011, a very loose network structure between the institutions and actors involved in governance existed. The Hualien Branch of the Forestry Bureau (HBFB) was in charge of the management of the forest park, and the TSC owned (and continues to own) the land and forest rights. Due to community forestry and other government-driven projects, Han-dominant community organizations began to emerge, operate, and interact with the HBFB. For the indigenous communities, only one actor who had been fighting for land rights for a long time participated, and he had a tense confrontation with the two government authorities, the HBFB and TSC. Most of the other tribe members refused to interact with the authorities. In addition, two research teams conducted research separately, without close coordination or cooperation. At that time, the researchers' work largely focused on natural science investigations, and governance issues were not examined, particularly the issue of land ownership. Academia did not interact with these indigenous peoples. Loose interaction relationships existed among the researchers, HBFB, TSC, and Han-dominant community organizations. Figure 2 presents the interaction of actors and the governance network during this period. 


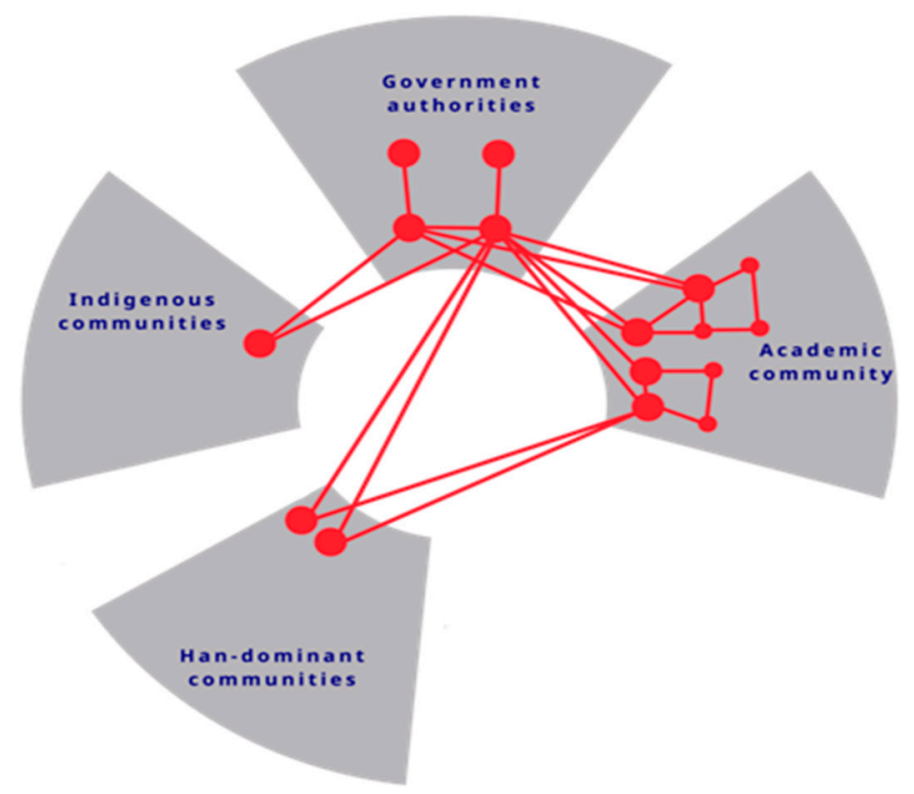

Figure 2. Governance network in 2011. Large dots represent major, active actors, and small dots represent actors with secondary significance. Lines between points represent interactive relationships.

\subsubsection{Governance Network between 2012 and 2013}

The indigenous protest in 2011 and change in the attitude of the Forestry Bureau toward local participation prompted it to begin to test very limited local community participation measures. From 2011 to 2013, the HBFB began to strengthen its interaction with indigenous communities. However, due to long-term disputes over land ownership and the resulting mistrust, most tribe members remained reluctant to communicate directly with the HBFB. Only one major actor continued to negotiate the land tenure issue, and other tribe members did not directly participate in forest park governance issues. The HBFB continued to promote community forestry projects in the DFA and sought to integrate the capacities of various communities to promote ecotourism. Because the Han-dominant communities generally welcomed this new community-based policy, interaction between Han-dominant community organizations and the HBFB began to intensify. In the academic sector, the NDHU Team began to conduct research projects and gradually strengthened the interaction with government authorities, Han-dominant community organizations, and indigenous communities. Because the NDHU team's research included governance issues of all major stakeholders, contact between the research team and indigenous people actors was initiated to gain a deeper understanding of the views of indigenous people. However, due to long-accumulated alienation, the interaction between the indigenous people and other stakeholders was relatively weak. Between the indigenous and Han-dominant community organizations, the previous isolation was maintained, and no substantive communication occurred between the two communities. The actor interaction and governance network during this period is presented by Figure 3 . 


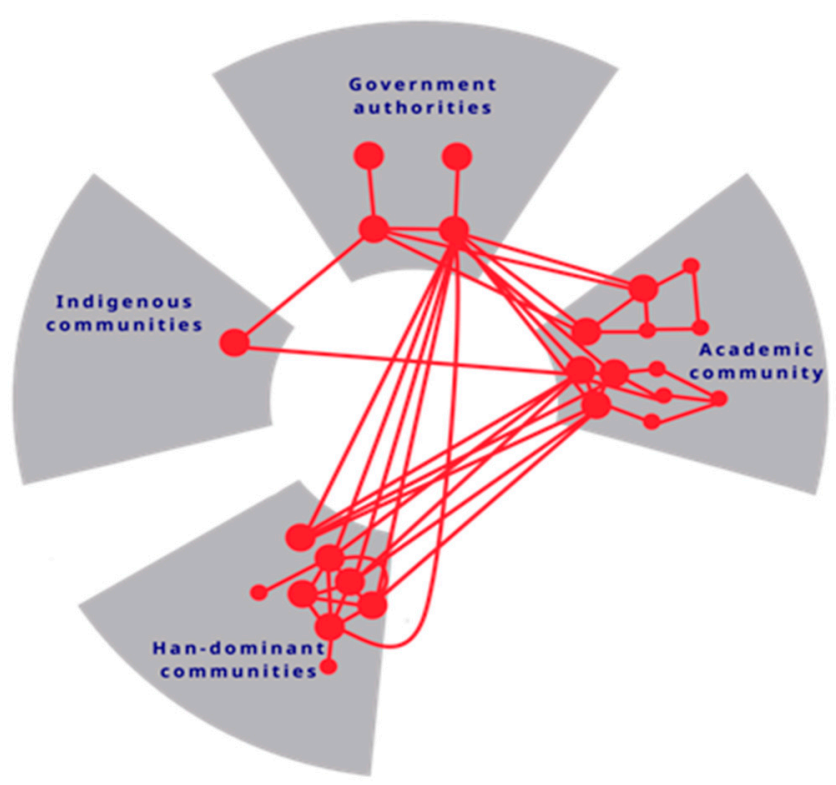

Figure 3. Governance network: 2012-2013.

\subsubsection{Governance Network between 2014 and 2015}

The period from 2014 to 2015 was critical for the development of the governance network. On the one hand, the HBFB developed a volunteer interpreter group in local communities. These volunteers proved to be a key social group actively participating in governance. On the other hand, the NDHU Team started to promote citizen science in 2014. People joining volunteer and citizen science groups gradually merged into a subnetwork. The citizen science network aimed primarily to fill gaps in natural science research in academia with local knowledge, through input from local volunteers. Citizen scientists, under the guidance of scholars, regularly monitored birds and amphibians in the DFA area and reported the results to academics and the HBFB. The evolving citizen science network, due to the roots of its origin, developed a close collaborative relationship with the HBFB, community organizations, and academia.

At the same time, the indigenous community network began to emerge. In 2012, the Hualien County Government set up a tribal affairs assembly mechanism for indigenous communities, and tribal chiefs met regularly to discuss tribal affairs. Two of the chiefs began to address DFA-related issues when they chaired meetings. Through regular meetings, their discussions increasingly reached consensus. Among the most crucial consensuses reached was that DFA land was the traditional territory of Amis people. This represents the fundamental "bottom line" for DFA governance from the indigenous perspective. Because of fundamental differences regarding land tenure claims, the indigenous network did not formally interacted with other subnetworks. However, due to the involvement of one tribal chief in the citizen science network during this period, the interaction between indigenous communities, the citizen science network, and academia, although still very limited, began to develop. The overall situation of the actor interaction and governance network during this period is presented using Figure 4 . 


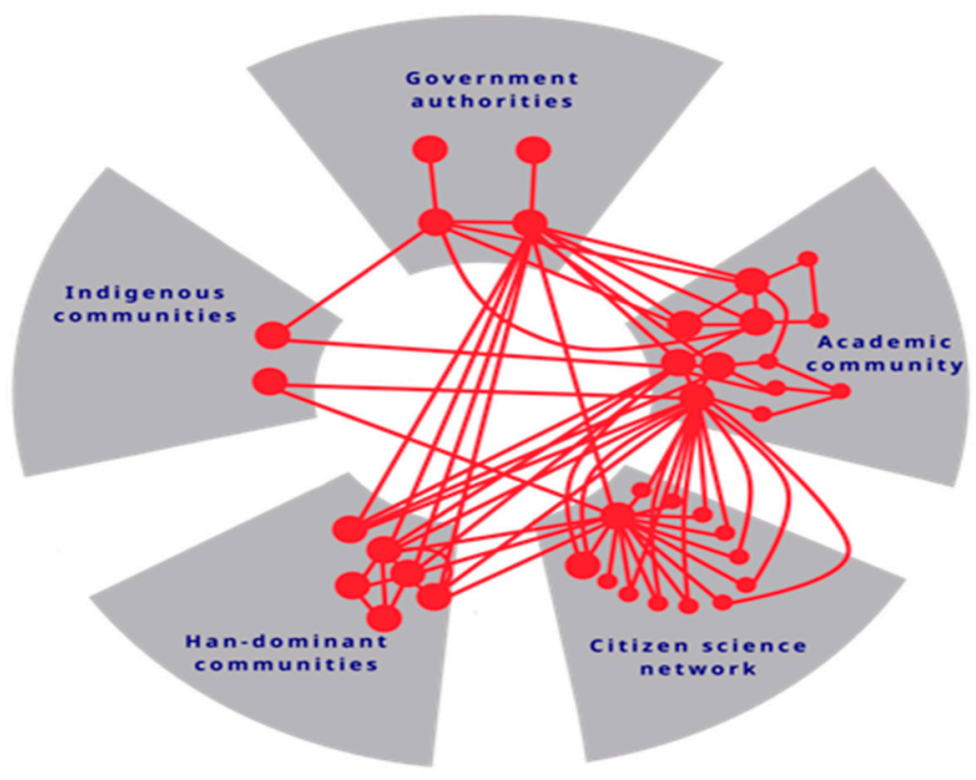

Figure 4. Governance network: 2014-2015.

\subsubsection{Governance Network after 2016}

Since 2016, due to the central government's Indigenous Historical Justice and Transitional Justice Policy, the Forestry Bureau has clearly revised its policy and has become more open to indigenous issues regarding natural resource use and co-management. In the DFA case, the HBFB accelerated its effort toward establishing a more inclusive governance mechanism and seeking to include primary stakeholders. This effort, based on the perspective of resilience-oriented governance, is also supported and pursued by the NDHU Team. An obvious major challenge was that the indigenous communities refused to engage in dialogue and cooperation with the existing state management regime. This led to the absence of indigenous representation in the governance network. The attitude of the indigenous communities is understandable, considering their extremely negative experiences of oppression by the state. The boycott can also continue to highlight the indigenous land and natural resource rights issues that Taiwan society generally ignores. However, this strategy is also a two-sided sword for the indigenous communities themselves. Continuing to be absent from the governance process actually means the absence of opportunities for the indigenous people's perspective to be considered, leading to the continued dominance of land use governance by mainstream social groups. Indigenous communities also lost an opportunity to foster their own governance capacity. The trend of large numbers of young indigenous people moving to urban areas has exacerbated these concerns. From a longer-term perspective, indigenous people must prepare their capacity in advance of the possible enactment of the Indigenous Autonomy Act.

To address this dilemma, the NDHU Team, as a change facilitator, took initiatives to discuss it with the tribal network. Based on long-term internal dialogues of tribal leaders and the bridging role of academia, the NDHU Team was able to host a series of discussions. The tribal network, after thorough consideration, agreed to join the meetings of the DFA governance platform, under the premise that the indigenous party insisted on its land ownership claim. The internal consensus of the tribal chiefs is that they can talk with other parties on improving DFA governance, while the land rights issue can, and should, be addressed in a stepwise manner. After 2017, stakeholders representing the public sector, indigenous communities, Han community organizations, citizen scientists, and academia regularly held governance platform meetings to discuss governance issues from both scientific and local knowledge perspectives. This platform integrates various stakeholders at different governance levels and facilitates cross-scale and cross-level interactions. 
Compared with the network structure prior to 2016, interactions among the multiple groups of stakeholders are now closer and more frequent, including interactions between indigenous communities and other stakeholders. Two new types of stakeholders also emerged. One is a network for a national protected areas plan, and the other is the ecotourism platform. Both these subnetworks are results of the Forestry Bureau's efforts, and the common purpose is to incorporate the DFA into the national network of protected areas while promoting ecotourism. Figure 5 presents the interaction of actors and governance network after 2016.

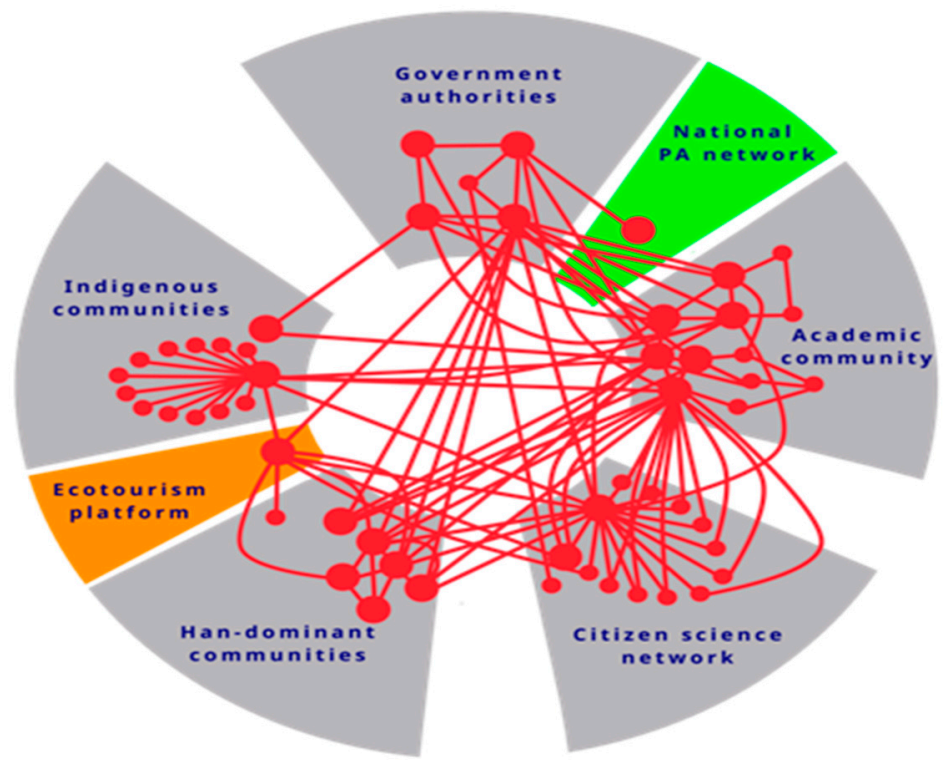

Figure 5. Governance network after 2016.

\subsection{Current Governance Outcome}

The main achievement of the governance platform to date has been the successful proposal of a new land use plan for the DFA forest park. In accordance with recent scientific research findings, all parties have agreed to designate the central part of the park as an ecological corridor connecting protected areas in the Central Mountain Range and the East Coastal Mountain Range. The area outside the corridor is to be used primarily for more intensive economic purposes, both consumptive and nonconsumptive, for example, tourism and agroforestry (see Figure 6). This latest blueprint is the result of a sophisticated compromise. The designation of the ecological corridor reflects the call of the proconservation parties, including the Forestry Bureau, citizen scientists, a majority of the Han community organizations, and most researchers. Promoting ecotourism is in line with the policy objectives of the Forestry Bureau and the interests of local communities, both Han and indigenous. The intensification of agricultural use mainly aims to meet the needs of the TSC and indigenous communities. This consensus is based on both scientific findings and local knowledge of land use practice. It also considers the preferences and needs of multiple stakeholders in the social system. On the whole, all parties have made compromises, and each has received some recognition of their concerns. 


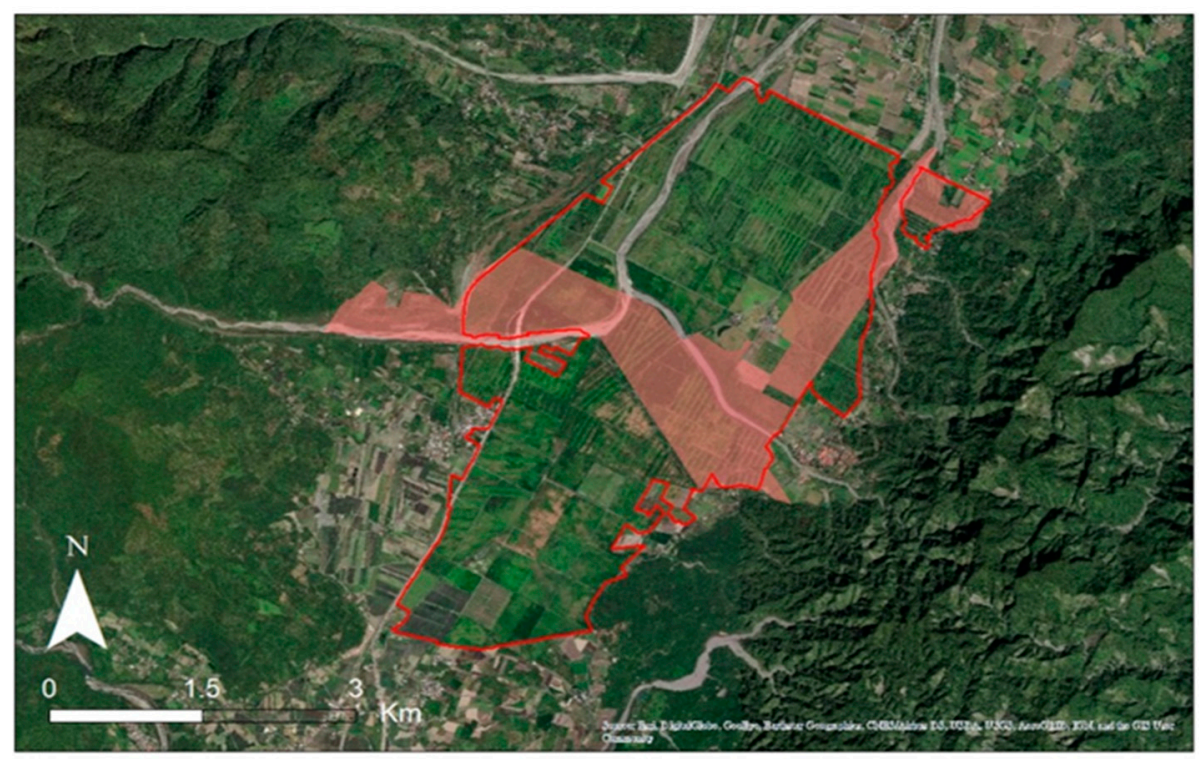

Figure 6. Future land use planning for the DFA forest park. The pink area represents the location of the planned ecological corridor. Source: I-Ming Chen (modified by the author).

Regarding the governance process, the following practices enabled a consensus to be reached. First, years of academic research allowed the discussion to proceed on a solid foundation. Hotspots of wildlife distribution, the economic and social needs of local communities, and differences in the perspectives of different ethnic groups were identified through research. Second, research findings and local knowledge supported stakeholder understanding of the basic information required for decision-making through governance platform meetings. Moreover, with the deliberate effort of major parties, the governance platform meeting included all key types of stakeholders; thus, key opinions could be considered. In the end, the opinions expressed in the governance meeting were fed back to the research team to assist them in revising the preliminary planning concept and making the revised blueprint acceptable to the stakeholders of the governance platform meeting. More precisely, compared with the previous governance model, the governance platform adopted was more participatory, deliberative, and knowledge-based. These characteristics facilitated the formation of a consensus among the stakeholders.

\section{Discussion}

Based on the case study, the main subtopics of the issue "resilience for whom" are discussed in this section as follows:

- Who and what drivers shape unequal political, economic, social, institutional, and ecological contexts;

- Who dominates resilience discourses and determines the problem-framing and problem-solving agenda;

- Who defines the scale and levels at which social-ecological system governance issues are addressed;

- Who determines the knowledge system used to define and solve problems;

- Who are the major agents of the governance process, who exerts influence on governance, and why; and

- Who decides the trade-offs among conflicting resilience governance goals.

\subsection{Who and What Drivers Shape Unequal Political, Economic, Social, Institutional, and Ecological Contexts}

The entry and rule of the modern state regime is the origin of the drastic transformation of the DFA social-ecological system. Indigenous land was nationalized by the state and subsequently used for the production of agricultural commodities for international trade. After Taiwan lost its international 
economic competitiveness in the cane sugar industry, the environmental conservation of DFA land was then conducted. Whether due to economic motivations or environmental considerations, the dominant political power of the modern state regime has fundamentally shaped land tenure, economic use patterns, social and demographic structures, governance institutions, and ecosystems. From the perspective of ethnic groups, dominant ethnic groups drive the modern state regime. In the era of Japanese rule, the dominant ethnic group was Japanese. In the current Taiwanese state, Han people dominate political power. Obviously, DFA's land tenure, economic utilization, and governance institutions reflect the interests of dominant ethnic groups.

\subsection{Who Dominates Resilience Discourses and Determines the Problem-Framing and Problem-Solving Agenda; Who Determines the Knowledge System Used to Define and Solve Problems}

After the afforestation in the early 2000s, the Forestry Bureau took control of the management of the DFA forest. For forest policy, the central government considers environmental conservation the first priority, supplemented by policy objectives of nonconsumptive uses such as ecotourism. This is also an era in which attention to climate change hasbeen initiated, as well as to carbon sequestration and resilience. In this context, the DFA forest is regarded as a tool for Taiwan to pursue international greenhouse gas regulation goals and enhance ecological resilience. Therefore, the central government has dominated the entire policy discourse pertaining to DFA land use. In addition, along with government policies, mainstream Taiwanese society also has a strong voice, hoping to reserve the DFA forest for conservation purposes. Conservationists, civil society organizations, most scholars, and active actors in Han communities involved in DFA governance support the government's conservation-oriented policy. In this discourse, national-scale ecological resilience and its potential benefits to Taiwanese society as a whole are arguably the central consideration.

Certainly, with the pressure brought by the indigenous movement and the policy revision of the Forestry Bureau itself, official and civil society mainstream discourses have also begun to adjust. Typical discourse emphasizes the need to take into account the public interests of the country (such as ecological resilience) as well as local concerns like livelihoods. Including local perspectives, this change has both sincere and hypocritical elements. It is happy to highlight the benefits that ecological resilience will bring to the locality, but at the same time it usually avoids discussing costs to local communities in the pursuit of this goal—especially the price paid by indigenous people. In such a power and discourse structure, DFA governance has mainly relied on (especially in the past) scientific and expert knowledge systems. Local knowledge, and especially indigenous knowledge systems, has long been excluded and ignored. This situation was notpartially corrected until the emergence of the new governance platform.

\subsection{Who Defines the Scale and Levels at Which Social-ecological System Governance Issues are Addressed}

Before 2000, the DFA region was regarded by the central government as a base to support national economic development, given the fact that the sugar industry was once one of Taiwan's main sources of foreign exchange income. This history has had both negative and positive socio-economic effects on various local communities, but these were incidental effects and not the focus of policy considerations. After 2000, the DFA was mandated by the central government and mainstream society to support national ecosystem resilience goals. This has also brought benefits and hidden costs to local communities, but again, these are incidental effects rather than the focus of the policy. From focusing on economic development to highlighting the social-ecological system's resilience, Taiwanese society has indeed undergone significant changes. However, what has not changed is that the DFA continues to be treated as a place that should support the country's overall goals. As for the fate of the DFA itself as a local social-ecological system, it is optional, according to policy needs.

After 2011, the pressure of the indigenous movement, policy changes within the Forestry Bureau, and the efforts of some academics have jointly contributed to the emergence of a new governance platform. This marked a milestone in revising previous national-scale viewpoints and an attempt to sincerely reconcile national- and local-scale views. Different groups of stakeholders 
have gradually joined the governance network, for different reasons. Han community organizations hope to develop ecotourism, whereas citizen scientists are motivated by conservation. The ecotourism platform developed later is basically a subnetwork derived from the first two. The three subnetworks, with experienced and active members of civil society, joined the governance network and collaborate with the public sector and academia. These actors are mostly wealthier, well-educated, and have sufficient work experience in an urban area. Their vision for the DFA is basically consistent with that of the public sector, and they are also familiar with how the public sector, civil society, and academia operate, so they can collaborate with other stakeholders relatively smoothly and play active and significant roles in the governance network. Their views, mixed with local and national scales, and actions therefore affect the governance process to a considerable extent.

\subsection{Who are the Major Agents of the Governance Process, Who Exerts Influence on Governance, and Who Decides the Trade-offs among Conflicting Resilience Governance Goals}

The Forestry Bureau continues to control the management authority of the forest park. This means that, without the support of the Forestry Bureau, major independent governance decisions cannot actually be made. Therefore, issues like the degree of local participation, agenda setting, the applied knowledge system, and the trade-offs between the main governance goals are carefully controlled by the Forestry Bureau. With the policy objectives of the central government, the Forestry Bureau adheres to the environmental conservation role of the DFA forest. On the premise of completing this task, it can adopt flexible measures, to some extent, regarding other goals, such as improving local livelihoods. Concurrently, academia serves as a producer of DFA-related academic knowledge and plays the role of a bridge among stakeholder groups and a facilitator of the governance platform. Academia has assisted in fostering several subnetworks such as citizen science and community organizations. Academia, as a bridge, has also critically contributed to the participation of indigenous communities in governance.

Due to negative historical experiences and the resulting mistrust of the state regime and mainstream society, indigenous communities joined the governance network relatively late, after choosing a long-term boycott position. Their joining added two key perspectives to the governance process. First, it let more people (some of whom for the first time) realize indigenous land issues and the social and economic costs suffered by indigenous peoples due to land deprivation. Second, it brought indigenous knowledge into governance decisions, especially cultural traditions that may balance land use and ecological conservation, as well as long-term on-site knowledge. Indigenous, scientific, and local knowledges provided by other subnetworks finally contributed to the redesign of DFA land use planning. That said, this remarkable progress does not mean that the participation of indigenous people was smooth. In fact, the process is filled with obstacles. Members of mainstream society still generally hold a suspicious attitude toward indigenous knowledge. Language barriers and culture gaps make it more difficult for tribal members to express their views in formal meetings and/or in informal dialogues. The migration of young people has resulted in tribes lacking active actors and a new generation of leaders. The impact of these obstacles was evident throughout the development of the governance network. At present, the governance network remains dominated by nonindigenous stakeholders in the number of active actors, network connectivity, and interaction frequency. Indigenous actors played a relatively marginal role.

A practical example can also be used to illustrate the challenges faced by indigenous people in governance. Indigenous representatives strongly advised that DFA land be more intensively used to provide economic and employment opportunities for surrounding indigenous communities, and this recommendation was accepted. Frankly, the reason this proposal was accepted was because the land owner, TSC, strongly supported the proposal to increase its economic revenues. Without strong support from other powerful stakeholders, a purely indigenous proposal would not be so readily accepted in a final determination. Another indigenous proposal was treated completely differently. Indigenous representatives have proposed that a piece of land be allocated to establish an ethnic food forest, because Amis people are known for their unique plant knowledge and plant utilization 
culture. However, most participants were obviously more interested in the ecological corridor than the ethnic food forest. This proposal ultimately received little response. This reflects the reality that ecological conservation remains more central to the governance process than the revitalization of indigenous culture.

\section{Conclusions and Policy Recommendation}

The DFA case is arguably representative of the complicated history that Taiwan has experienced with regard to indigenous land issues and the fact that indigenous people were and remain oppressed. Under the colonial regime and rise of the modern state, DFA land was snatched and registered as owned by the state. To meet the national development goals of different periods, this land was assigned with varying policy tasks. In the era of economic development, the land was used to produce commercial agricultural products of high economic value. In today's era, emphasizing global environmental changes, the land was converted into forests to enhance ecological resilience and to serve as support for the resilience of the national social-ecological system. Whether the focus is on the well-being of social systems or ecological resilience, the needs of indigenous people were dismissed by mainstream society's dominant powers.

This study determined that, for a long period, the central government determined "resilience for whom." The central government shaped the political, economic, social, institutional, and ecological contexts; they dominated resilience discourses and determined the problem-framing and problem-solving agenda; they defined the scale and levels at which social-ecological system governance issues were to be addressed; and they determined the knowledge system used to define and solve problems. This situation has changed, somewhat. The current DFA governance institution has begun to incorporate the views of multiple stakeholders, and, to a limited extent, allow more governance power to these stakeholders. More active, mostly local actors are participating in the governance process. These new participants have begun to contribute their views on resilience discourses and have exerted influences on governance and trade-offs among differing governance goals. This is certainly meaningful progress that can help people achieve a finer balance between national and local perspectives. Findings of this article demonstrated, however, that under the established political, economic, institutional, social, and cultural structures, dominated by Han people, the current participatory governance regime primarily reflects the power, views, and interests of Han society. On the whole, the governance of the DFA can be said to have changed from the "resilience for the public" mode to the "resilience for both the public and local people" mode. Regardless of the mode, though, the main beneficiaries are Han people, not indigenous people. In fact, indigenous people almost always pay a disproportionate price in decision-making. Final questions arise: whose rights should be actively recognized and safeguarded, and what measures can the people take to improve the process of rights recognition and protection?

For the indigenous communities in the DFA, under the established structure, the pursuit of their own social-ecological system resilience is long and extremely difficult. Both in an era of economic development and an era of highlighted social-ecological systems, this struggle is the same. The emergence and goodwill of the participatory governance model does help indigenous people express their views and substantially influence the governance process and outcomes, but it is far from sufficient to address the roots of the "resilience for mainstream society" phenomenon: the established land ownership and subsequent governance authority. Obviously, affirmative action is sorely needed to effectively recognize and safeguard indigenous autonomy.

Redefining land ownership and returning land rights to indigenous people is undoubtedly a highly challenging political issue in Taiwanese society, in which Han people make up $97 \%$ of the population. A nationwide, systematic solution relies on the Indigenous Land and Ocean Act under discussion in parliament. However, due to the complexity of the issue, the passage of this bill is likely remote and far from certain. Before taking that step, people could consider other institutional pathways. A practical example, the case of Molisaka, near the DFA, might be a model worth considering. Molisaka is a traditional territory of the indigenous Truku people that was too classified as state-owned land and 
managed by the Forestry Bureau. After years of academic investigation, this land was confirmed by the Indigenous Historical Justice and Transitional Justice Committee appointed by the Presidential Office to be indigenous [43]. Administrative procedures for returning land are in progress. A governance committee has also been formally established, with more than half of its representatives indigenous. This article suggests that the DFA case follows the same approach. A formal land history survey through an official proposal of the Indigenous Historical Justice and Transitional Justice Committee can be conducted, and after confirming the historical facts of the territory, the legal and administrative procedures for land return can be initiated. This may open a new era of "resilience for indigenous people" in traditional indigenous territories as early as possible.

Emphasizing "resilience for indigenous people" is of significant importance not only to indigenous people but also for the DFA region and the overall social-ecological system resilience of Taiwan. For years, when discussing social-ecological resilience in Taiwanese society, people have focused on ecological resilience and the well-being of Han society. This deficiency should be corrected. From a positive perspective, following synthesis of the comprehensive review by Chapin et al. [44], I suggest that "resilience for indigenous people" helps improve the social-ecological resilience of individual regions and of Taiwan as a whole. It enhances the capacity of crucial segments of society, particularly that of vulnerable groups, to adapt to adverse impacts. It sustains cultural diversity and helps maintain a diversity of options that could be crucial to social-ecological resilience. Social cohesion, trust, networking, and communication among various groups can be fostered to adapt governance that realizes sustainable solutions. All these will contribute to the transformation of all of society into a more resilient social-ecological system.

Funding: This research was funded by the Ministry of Science and Technology, Taiwan, grant numbers MOST 102-2621-M-259-001; MOST 103-2621-M-259-004; MOST 104-2621-M-259-004; MOST 105-2621-M-259-001; MOST 106-2621-M-259-001; MOST 107-2621-M-259-001. This work was also partly supported by the National Research Foundation of KoreaGrant funded by the Korean government (NRF-2017S1A3A2067220), which covered the literature analysis costs and travel expenses incurred when attending the international conference "Practicing the Commons in East Asia: From Possibility to Reality", held in Jeju, Korea, February 15-16, 2017.

Acknowledgments: The author is heartily grateful for the team work and inspiration provided by all research team members in the joint research project entitled "Social-Ecological System Resilience in Central Eastern Rift Valley: The Role of Danungdafu Forestation Area." Special thanks are given to all interviewees, including local community members, government officials, non-governmental organization practitioners, and scholars, for their generous support and feedback. The author also heartily thanks I-Ming Chen for generously providing the blueprint of the DFA Ecological Corridor. Earlier versions of this article were presented at the International Conference "Practicing the Commons in East Asia: From Possibility to Reality," Jeju, Korea, 15-16 February 2017, and the 17th Global Conference of the International Association for the Study of the Commons (IASC), Lima, Peru, 1-5 July 2019. The author thanks the panel participants at these conferences for their valuable comments. The author also thanks two anonymous reviewers for their constructive suggestions which improve the content of the article.

Conflicts of Interest: The author declares no conflict of interest. The funders had no role in the design of the study; in the collection, analyses, or interpretation of data; in the writing of the manuscript; or in the decision to publish the results.

\section{References}

1. Folke, C. Resilience (Republished). Ecol. Soc. 2016, 21, 44. [CrossRef]

2. Chapin, F.S., III; Folke, C.; Kofinas, G.P. A framework for understanding change. In Principles of Ecosystem Stewardship: Resilience-based Natural Resource Management in a Changing World, 1st ed.; Chapin, F.S., III, Kofinas, G.P., Folke, C., Eds.; Springer: New York, NY, USA, 2009; pp. 3-28.

3. Berkes, F.; Folke, C. Linking Social and Ecological Systems: Management Practices and Social Mechanisms for Building Resilience, 1st ed.; Cambridge University Press: Cambridge, UK, 1998.

4. Walker, B. Resilience: What it is and is not. Ecol. Soc. 2020, 25, 11. [CrossRef]

5. Kofinas, G.P.; Chapin, F.S., III. Sustaining livelihoods and human well-being during social-ecological change. In Principles of Ecosystem Stewardship: Resilience-based Natural Resource Management in a Changing World, 1st ed.; Chapin, F.S., III, Kofinas, G.P., Folke, C., Eds.; Springer: New York, NY, USA, 2009; pp. 55-75. 
6. Armitage, D.; Béné, C.; Charles, A.T.; Johnson, D.; Allison, E.H. The interplay of well-being and resilience in applying a social-ecological perspective. Ecol. Soc. 2012, 17, 15. [CrossRef]

7. Lebel, L.; Anderies, J.M.; Campbell, B.; Folke, C.; Hatfield-Dodds, S.; Hughes, T.P.; Wilson, J. Governance and the capacity to manage resilience in regional social-ecological systems. Ecol. Soc. 2006, 11, 19. [CrossRef]

8. Cote, M.; Nightingale, A.J. Resilience thinking meets social theory: Situating social change in socio-ecological systems (SES) research. Prog. Hum. Geogr. 2012, 36, 475-489. [CrossRef]

9. Berkes, F. Coasts for People: Interdisciplinary Approaches to Coastal and Marine Resource Management, 1st ed.; Routledge: New York, NY, USA, 2015.

10. Ingalls, M.L.; Stedman, R.C. The power problematic: Exploring the uncertain terrains of political ecology and the resilience framework. Ecol. Soc. 2016, 21, 6. [CrossRef]

11. Barrios, R.E. Resilience: A commentary from the vantage point of anthropology. Ann. Anthro. Pract. 2016, 40, $28-38$. [CrossRef]

12. Cretney, R. Resilience for whom? Emerging critical geographies of socio-ecological resilience. Geogr. Com. 2014, 8, 627-640. [CrossRef]

13. Walsh-Dilley, M.; Wolford, W.; McCarthy, J. Rights for resilience: Food sovereignty, power, and resilience in development practice. Ecol. Soc. 2016, 21, 11. [CrossRef]

14. Fabinyi, M.; Evans, L.; Foale, S.J. Social-ecological systems, social diversity, and power: Insights from anthropology and political ecology. Ecol. Soc. 2014, 19, 28. [CrossRef]

15. McGinnis, M.D.; Ostrom, E. Social-ecological system framework: Initial changes and continuing challenges. Ecol. Soc. 2014, 19, 30. [CrossRef]

16. Brandt, F.; Josefsson, J.; Spierenburg, M. Power and politics in stakeholder engagement: Farm dweller (in)visibility and conversions to game farming in South Africa. Ecol. Soc. 2018, 23, 32. [CrossRef]

17. Herrera, H. Resilience for whom? The problem structuring process of the resilience analysis. Sustainability 2017, 9, 1196. [CrossRef]

18. Westley, F.R.; Tjornbo, O.; Schultz, L.; Olsson, P.; Folke, C.; Crona, B.; Bodin, Ö. A theory of transformative agency in linked social-ecological systems. Ecol. Soc. 2013, 18, 27. [CrossRef]

19. Moore, M.; Westley, F. Surmountable chasms: Networks and social innovation for resilient systems. Ecol. Soc. 2011, 16, 5. [CrossRef]

20. Ayers, A.L.; Kittinger, J.N.; Vaughan, M.B. Whose right to manage? Distribution of property rights affects equity and power dynamics in comanagement. Ecol. Soc. 2018, 23, 37. [CrossRef]

21. McDermott, C.L.; Ituarte-Lima, C. Safeguarding what and for whom? The role of institutional fit in shaping REDD+ in Mexico. Ecol. Soc. 2016, 21, 9. [CrossRef]

22. Long, J.W.; Lake, F.K. Escaping social-ecological traps through tribal stewardship on national forest lands in the Pacific Northwest, United States of America. Ecol. Soc. 2018, 23, 10. [CrossRef]

23. Ministry of Science and Technology. Available online: https://www.most.gov.tw/folksonomy/detail/5d431ca7761c-41dc-b679-5c9a23174abe?1=CH\&utm_source=rss (accessed on 15 May 2020).

24. The Council of Agriculture. Available online: https://kmweb.coa.gov.tw/theme_data.php?theme=news\& sub_theme=attention $\&$ id $=49075$ (accessed on 15 May 2020).

25. The Taiwan Forestry Research Institute. Available online: https://www.tfri.gov.tw/main/news_in.aspx?siteid= \&ver=\&usid=\&mode=\&mnuid=5425\&modid=529\&nid=30214\&noframe=\&cid=77 (accessed on 15 May 2020).

26. The Ministry of the Interior. Available online: http://pdmcb.nfa.gov.tw/dc/intro (accessed on 15 May 2020).

27. The Ministry of Economic Affairs. Available online: https://www.moea.gov.tw/MNS/populace/Policy/Policy. aspx?menu_id=32800\&policy_id=10 (accessed on 15 May 2020).

28. Kang, P. Colonial Contact and Imperial Periphery: History of the Austronesian Population of Hualien from the 17c to the 19c, 1st ed.; Dao Xiang: Taipei, Taiwan, 1999.

29. Indigenous Historical Justice and Transitional Justice Committee, the Presidential Office. Available online: https://indigenous-justice.president.gov.tw/EN (accessed on 28 June 2020).

30. Resilience Alliance. Assessing Resilience in Social-Ecological Systems: Workbook for Practitioners, Version 2.0, 2010. Available online: http://WWW.resalliance.org/3871.php (accessed on 29 June 2020).

31. Chang, C.Y.; Tsai, B.Y.; Liu, J.H.; Lee, J.T.; Wang, M.H.; Kuan, D.W.; Lin, Y.R.; Ni, C.C.; Fan, Y.J.; Pei, J.C.; et al. Research Report on the Traditional Territory of Indigenous Peoples; Council of Indigenous People, Executive Yuan: Taipei, Taiwan, 2003; pp. 207-216. 
32. Huaung, Y.H. Hometown of Others: On Displacement and Autonomy Movement of Karowa indigenous People from the Perspective of Space Hegemony. Master's Thesis, National Dong Hwa University, Hualien, Taiwan, 2003.

33. Shizue, F. Governing Indigenous People: The Plan of Governing Taiwan by Japan, 1st ed.; WenYingTang: Taipei, Taiwan, 1997.

34. Huang, Y.H. Multiple Boundaries as Palimpsests: The Shifting Landscapes of Native Land Rights in Taiwan. Ph.D. Dissertation, National Dong Hwa University, Hualien, Taiwan, 2014.

35. Chung, S.H. A History of the Development of Cane Sugar Industry in Hualien: 1899-2002, 1st ed.; East Taiwan Research Association: Taitung, Taiwan, 2009.

36. Chen, A.H.; Chen, L.M. Promoting the afforestation policy in the plain area. Taiwan For. J. 2002, 28, 18-21.

37. Hualien Branch of Forestry Bureau. Management Plan of the Danungdafu Forest Park; Hualien Branch of Forestry Bureau: Hualien, Taiwan, 2015.

38. Koh, C.N.; Hsu, S.H.; Chen, I.M.; Yang, Y.R. Contribution of Danungdafu plain afforestation to conservation of native biodiversity: The example of birds. Fore. Re. News. 2019, 26, 41-44.

39. Lin, B.Y. A Discussion on the Habitat Functions of the Danungdafu Forest Park to Larger Mammals. Master's Thesis, National Dong Hwa University, Hualien, Taiwan, 2018.

40. Lee, C.H.; Wang, C.H. Estimating residents' preferences of the land use program surrounding forest park, Taiwan. Sustainability 2017, 9, 598. [CrossRef]

41. Tai, H.S. Cross-scale and cross-level dynamics: Governance and capacity for resilience in a social-ecological system in Taiwan. Sustainability 2015, 7, 2045-2065. [CrossRef]

42. Lu, D.J. Indigenous people and community forestry. Taiwan J. For. Sci. 2009, 16, 28-30.

43. Clarify the Process of Land Loss of Indigenous People: Take Lintianshan Forestry Cultural Park of Forestry Bureau as an Example. Available online: https://www.president.gov.tw/NEWS/24156 (accessed on 28 June 2020).

44. Chapin, F.S., III; Carpenter, S.R.; Kofanis, G.P.; Folke, C.; Abel, N.; Clark, W.C.; Olsson, P.; Smith, D.M.S.; Walker, B.; Young, O.R.; et al. Ecosystem stewardship: Sustainability strategies for a rapidly changing planet. Tren. Ecol. Evolut. 2009, 25, 241-249. [CrossRef] [PubMed] 